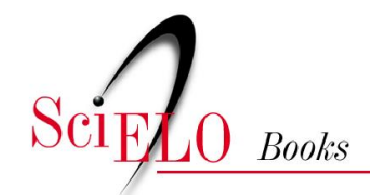

\title{
A política social brasileira na conjuntura da crise internacional
}

\author{
Sheyla Suely de Souza Silva
}

SciELO Books / SciELO Livros / SciELO Libros

SILVA, SSS. A política social brasileira na conjuntura da crise internacional. In DAVI, J., MARTINIANO, C., and PATRIOTA, LM., orgs. Seguridade social e saúde: tendências e desafios [online]. 2nd ed. Campina Grande: EDUEPB, 2011. pp. 21-39. ISBN 978-85-7879-193-3. Available from SciELO Books < http://books.scielo.org>.

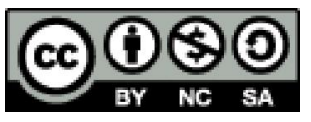

All the contents of this work, except where otherwise noted, is licensed under a Creative Commons Attribution-Non Commercial-ShareAlike 3.0 Unported.

Todo o conteúdo deste trabalho, exceto quando houver ressalva, é publicado sob a licença Creative Commons Atribuição Uso Não Comercial - Partilha nos Mesmos Termos 3.0 Não adaptada.

Todo el contenido de esta obra, excepto donde se indique lo contrario, está bajo licencia de la licencia Creative Commons Reconocimento-NoComercial-CompartirIgual 3.0 Unported. 


\section{A política social brasileira na conjuntura da crise internacional}

Sheyla Suely de Souza Silva

\section{Introdução}

Desenvolvido no decorrer do Curso de Doutorado em Serviço Social pela Universidade Federal de Pernambuco (UFPE), este artigo esboça uma atualização da discussão sobre a política social brasileira, tentando situá-la na atual conjuntura de uma crise econômica planetária sem precedentes, explicitada pelo crash de setembro de 2008. Mais que um trabalho eminentemente teórico, nossa intenção é refletir de forma ainda introdutória sobre os eventos atuais, na perspectiva da discussão do papel do Estado e das tendências anunciadas para a política social brasileira, nesses tempos de crise, o que nos permite apontar, como principais conseqüências para as políticas sociais públicas, o acirramento das disputas pelos recursos públicos como pressuposto exclusivo do capital e o estreitamento dos laços de solidariedade do Estado brasileiro ao setor privado. 


\section{Pressupostos gerais: três décadas de crise do capitalismo e a recente crise do neoliberalismo}

Os anos de 1970 marcaram o início do declínio dos chamados trinta gloriosos anos de capitalismo democrático, durante os quais, a combinação Estado de Bem-Estar Social e modo de produção fordista garantiu - num contexto de onda larga expansiva - a recuperação e manutenção da taxa de lucro do capital e trouxe ganhos aos padrões materiais de vida dos trabalhadores ${ }^{1}$. Naqueles anos assistimos, também, à derrocada das experiências do socialismo real.

A onda inflacionária e o choque do petróleo, vivenciados em meados daquela década, foram indícios do novo período de crise, quando a eficácia da estratégia anticíclica do pacto fordista/ keynesiano se exauria e o capital propunha, então, a liberdade de mercado, a alteração da estrutura produtiva e a reforma do Estado, articulando e pondo em cena o neoliberalismo:

O capitalismo, 'superados' os principais obstáculos à sua continuidade, entre eles, o desmonte objetivo dos estados 'socialistas', coloca em questão o chamado bem-estar social. Os capitalistas liberam-se de todo e qualquer compromisso com a satisfação das necessidades reais da população e da ampliação da cidadania. Para tal, levaram a extremo a idéia de liberdade do mercado (DIAS, 1998, p. 49).

1 É preciso ressaltar que, em escala mundial, estes ganhos não atingiram as massas de trabalhadores em geral de forma homogênea. Se no centro do sistema eles alcançaram características de universalidade, redistributividade e pleno emprego, por exemplo, nos países periféricos, em geral, forjaram-se como um tal "estado de mal estar", conformado por benefícios seletivos e corporativistas que jamais alcançaram um patamar de universalidade, não atingiram o pleno emprego e não superaram as práticas distributivas, responsabilizando única e exclusivamente os próprios trabalhadores pela reprodução da força de trabalho. 
Globalização, reestruturação produtiva e reforma do Estado compõem a tríade central da ofensiva neoliberal que, ao longo das últimas três décadas - tanto no plano material/objetivo, quanto no plano ideológico/subjetivo - disseminaram, justificaram e operacionalizaram os interesses e as estratégias do capital na sua investida em prol de uma tentativa de superação da crise estrutural a que se encontra submetido.

Para Martins (1997, p. 14), dentre os efeitos maléficos do processo de globalização deu-se a destruição das condições que tornariam possível o regime democrático, tendo em vista que este processo conferiu ampla liberdade para o capital em escala planetária, mas restringiu a liberdade do trabalho ${ }^{2}$ e submeteu os trabalhadores a uma larga desproteção social, impondo, em especial aos países periféricos, a retração dos direitos sociais e trabalhistas.

Martins (1997) desmistifica o conceito e a objetivação histórica da globalização, evidenciando seu uso ideológico, uma vez que, para o autor, tal fenômeno não se confunde - como quiseram convencer os neoliberais - nem com uma internacionalização, nem com uma mundialização do capital. $\mathrm{O}$ autor ressalta que o capital internacionalizado não tem pátria nem defende bandeiras. E assim, ao invadir os territórios nacionais, tais capitais não estabelecem necessariamente relações "inter-nações", mas entre unidades do próprio capital, ora em articulação, ora em competição.

Ainda para o autor (1997), a mundialização do capital pressuporia uma regulamentação mundial da economia, submetendo seu movimento a regras, metas e consensos mundialmente formulados.

2 Observe-se que o capital tem o pleno direito de ir e vir, mas os trabalhadores são barrados nas "velhas" fronteiras geográficas da Europa e dos EUA. Para legalizar essas restrições, foi aprovada recentemente pela União Européia - em 18 de junho de 2008 - a "diretriz de retorno", que passará a vigorar em 2010, transformando em crime a imigração ilegal, o que "reflete o colapso do sistema jurídico humanista europeu diante da crise econômica" (BONVICINO, 2008). 
De fato, embora tenha organizado alguns blocos político-econômicos - a exemplo da União Européia - não há uma regulamentação mundial e, em algumas regiões, o capital requer exatamente o oposto e se robustece nas fragilidades das regulamentações nacionais que lhe permitem a incorporação de novos nichos de lucro através, por exemplo, da exploração do trabalho infantil e escravo e da apropriação/destruição da natureza, em países que não dispõem de uma legislação e/ou de um aparato jurídico-institucional que proteja a sociedade, a cultura local e o meio ambiente; bem como da usurpação de mão de obra barata, em países que não qualificam nem protegem seus trabalhadores, não produzem altas tecnologias e, por isso mesmo, entram de forma subalterna neste processo de globalização e de nova divisão internacional do trabalho ${ }^{3}$.

Por outro lado, o surgimento de uma "macro-estrutura-financeira" internacional qualificou o processo de globalização como uma crescente financeirização do capital, marcada pela gestão e especulação sobre recursos públicos e privados, oriundos, inclusive - e, talvez, principalmente - das arrecadações e das dívidas públicas nacionais, ameaçando a liquidez e a soberania de cada nação, exposta cada uma delas às inflexões das crises econômicas norteamericanas, como vimos constatando nos últimos meses.

3 Em sua obra "O Novo Imperialismo", Harvey (2004) alerta para uma recorrente investida do capital em estratégias de espoliação, como recurso para superação dos períodos de crise. $\mathrm{Na}$ sua mais recente recorrência à espoliação - desde o pós-1973 -, o capital conta com o apoio dos Estados, através dos quais se acirram a privatização dos recursos naturais; a expropriação das terras comuns e a privatização dos ativos dos Estados nacionais (dentre outros elementos), como condição da integração dos países periféricos ao sistema capitalista globalizado. 


\section{Crise da economia mundial e da hegemonia neoliberal num contexto de devastação da natureza, do emprego e das conquistas do trabalho}

A teoria de que o mercado seria o regulador social nato e autônomo - em contraposição a uma proposta de Estado interventor - jamais chegou a consolidar-se historicamente e dá sinais claros de crise e de refutamento, desde a crise asiática de 1997 até os últimos eventos inaugurados no crash de setembro de 2008.

Os eventos atuais recolocam na agenda do dia a discussão clássica das ciências sociais sobre o papel do Estado e evidenciam a fragilidade das teses que sustentaram, nas últimas três décadas, o discurso e a ofensiva neoliberal.

O "dilúvio neoliberal" - que, frente à retração da capacidade organizativa e propositiva do trabalho ${ }^{4}$ e à inauguração de uma nova onda larga recessiva do capital, desenvolveu clara ofensiva contra a intervenção do Estado na economia e na proteção social - teve dois epicentros, engendrados por propostas de governo similares, cuja diretriz central era o desmantelamento do bem-estar-social, por Reagan, nos EUA e por Thatcher, na Inglaterra ${ }^{5}$, sob o discurso da virtude natural do mercado como regulador social, em detrimento do Estado, cuja intervenção na economia e nas relações sociais seria artificial, autoritária, maléfica e perdulária.

4 Referimo-nos, em especial, à derrocada das experiências do socialismo real e, com ela, ao chamado "esgotamento das energias utópicas", marcado pela ausência de uma elaboração e defesa de projetos societários alternativos ao capitalismo.

5 Salvas as significativas diferenças entre os modelos americano e inglês de bemestar social, é válido ressaltar que ambos os governos (Reagam e Thacher) encontraram resistências ao seu desmantelamento, comprometendo a investida neoliberal naquelas sociedades, em especial na Inglaterra, aonde, segundo King (1988), desenvolveu-se uma "cultura do direito a ter direitos". 
A partir dessas duas "tentativas-piloto", a ofensiva neoliberal, sob a batuta das principais agências internacionais de crédito Banco Mundial (BM) e Fundo Monetário Internacional (FMI) - e referendada pelo consenso de washington, alastrou-se impositivamente sobre as economias periféricas, através de acordos e tratados, tomados como requisitos para a concessão de empréstimos, a negociação de dívidas e/ou a redução de embargos econômicos e políticos.

Para Belluzzo (2008a), o neoliberalismo não tirou o Estado de cena, apenas mudou sua agenda em favor de utilizar o poder político e fiscal dos Estados nacionais para fortalecer os sistemas empresariais, e:

Nessa toada, as reformas atropelaram as instituições destinadas a garantir a segurança econômica e social da maioria assalariada ou dependente. Os neo-reformistas cuidaram de transferir os riscos para os indivíduos dispersos (BELLUZZO, 2008a, p. 38).

Tais reformas consolidaram os pressupostos privatistas do capital.A apropriação da ciência e da tecnologia como forças produtivas garantiu a substituição em larga escala do trabalho vivo e inaugurou o desemprego estrutural, deixando à margem amplas parcelas de trabalhadores em plenas capacidades produtivas e, inclusive, amplamente qualificados, em nome de uma maior lucratividade ${ }^{6}$. O dilúvio foi devastador. Suas estratégias de reestruturação produtiva e de reforma dos Estados - dando suporte a uma globalização marcada pela desigualdade na inserção dos países ricos, emergentes ou pobres - destruíram as conquistas do trabalho, os direitos sociais e o emprego; alastraram a fome e inauguraram a crise dos alimentos; ampliaram as desigualdades sócio-econômicas e, sob sua égide, a devastação da natureza extremou-se a tal ponto que colocou a

6 Para Castel (1998) esta crise da sociedade salarial criou, ao menos na perspectiva de um mundo neoliberal, os supranumerários ou inúteis para o mundo. 
sociedade sob a ameaça - possivelmente irreversível - de extermínio do planeta e da humanidade ${ }^{7}$.

Por outro lado, tal ofensiva e suas conseqüências sequer justificaram-se na superação da crise econômica. Pelo contrário, o crash de setembro de 2008 foi apenas o sintoma mais evidente do caráter estrutural e irreversível da crise contemporânea do capital e da ineficiência da estratégia neoliberal.

O apelo a um retorno da intervenção do Estado na economia vem sendo clamado pelos próprios ícones do discurso neoliberal e o mercado é o grande beneficiário do socorro estatal diante do crash. Já no primeiro trimestre de 2008 , representantes do próprio FMI e do BM recapitulavam seus discursos e alardeavam a evidente necessidade de intervenção pública na economia ${ }^{8} ; \operatorname{logo}$ depois, os EUA estatizaram duas grandes agências hipotecárias - a Fannie Mae e a Fredie Mac - para salvá-las da falência. Após o crash, esses apelos priorizaram uma solicitação de socorro financeiro aos grandes bancos americanos e europeus, abalados pelas astronômicas perdas

7 Mészáros (2002) considera que as contínuas estratégias do capital para superar suas crises cíclicas e imanentes colocaram o sistema capitalista diante de limites absolutos (e intransponíveis) à sua expansão; o que requer o urgente enfrentamento do dilema da humanidade entre superar o capital ou deparar-se com a ameaça irrevogável à sobrevivência humana, tendo em vista a atual devastação da natureza em prol do lucro. Citando Marx, Benjamin (2008) esclarece que a financeirização da acumulação capitalista conduziria, necessariamente, à instabilidade, uma vez que a valorização sem trabalho é fictícia e arbitrária a qualquer potencial civilizatório no âmbito do capitalismo.

8 Líderes dessas agências de crédito, inclusive, apelaram aos países desenvolvidos uma ajuda de 500 milhões de dólares para financiar a compra de sementes em países ameaçados de fome (COSTA, 2008a) 
na especulação imobiliária americana e, posteriormente, nas bolsas de valores do mundo inteiro?

O Estado não traiu seu papel histórico de salvaguardar os interesses dos proprietários do capital e, no mundo inteiro, elaborou e implementou "pacotes salva bancos", para, mais uma vez, socializar com os trabalhadores/contribuintes as perdas dos mais ricos, os quais, segundo Belluzzo (2008b, p. 40),

[...] estão certos em esperar socorro. Pois sabem que, enquanto cometerem os mesmos erros coletivamente - como fazem os 'banqueiros sensatos' -, o setor público precisará prestar socorro. Os banqueiros têm condições de manter a economia e a sociedade democrática como suas reféns [...]. Os Governos não têm alternativa: precisam ajudar os bancos

O Estado emerge mais forte que nunca nas atividades econômicas e os bancos centrais do mundo inteiro despejam bilhões de dólares (e esses não são fictícios; não advém da especulação financeira, mas da esfera da produção, ou seja, da "velha e confiável" exploração do trabalho!) para salvar os mercados.

Segundo Pinheiro (2008a, p. 26), o Federal Reserve (Fed) (Espécie de Banco Central dos EUA), apenas em setembro de 2008, anunciou 180 bilhões de dólares em linhas de financiamento; o Banco da Inglaterra, 45 bilhões; o Banco Central Europeu, 55 bilhões. No Brasil, o Estado fortalece seus sólidos (para alguns, até promíscuos) laços de solidariedade com o mercado, como veremos a seguir.

9 Analistas financeiros já admitem que a origem da turbulência econômica teria sido a ausência de regulação sobre o mercado (PINHEIRO, 2008a). Para Belluzzo (2008c, p. 34), "A omissão das autoridades diante das pirotecnias dos mercados é a marca registrada do capitalismo americano”. Essa omissão explicitou-se claramente na ampla realização das hipotecas subprime que deram origem ao último crash. 


\section{Pressupostos particulares: persistência neoliberal e outros agravantes da crise na particularidade da realidade brasileira}

$\mathrm{Na}$ particularidade da realidade brasileira, a origem colonial, a estrutura latifundiária, a cultura escravista, a dívida externa são aspectos que historicamente vêm condicionando o país a uma relação de submissão ao capital internacional e a uma conseqüente permeabilidade aos pressupostos da ofensiva neoliberal, estreante no país a partir dos anos de 1990.

Aqui, a ofensiva neoliberal não encontrou uma cultura do direito e da cidadania, pois as conquistas limitaram-se à formalidade, não sendo substancialmente vivenciadas pelas massas trabalhadoras, o que inibe resistências à perda dos direitos conquistados na Constituição Federal de 1988, já que nunca foram efetivamente experimentados, pois, a agenda universalista pactuada na Carta Magna esgotou-se antes mesmo de ser implementada (RAICHELLIS, 1998), anunciando a brevidade e fragilidade da reforma democrática, em especial no que diz respeito ao acesso dos trabalhadores a uma fatia da riqueza socialmente produzida, pela via da universalização das políticas sociais e da inauguração da seguridade social brasileira.

Nessa conjuntura, as três principais ofensivas do neoliberalismo - globalização, reestruturação produtiva e reforma do Estado - aliadas às características de desigualdades e iniqüidades que marcam a nossa formação sócio-econômica e à estratégia identificada por Mota (1995) como uma cultura da crise - subjugaram, cooptaram e conquistaram diferentes sujeitos sociais na adesão ao projeto societário do capital, tornando-o hegemônico, ao tempo em que agudizaram a questão social brasileira. 
No âmbito da globalização, o Brasil tem uma inserção subordinada, imposta pela subserviência às agências internacionais de crédito; pelas suas fragilidades na produção de tecnologias avançadas e pelo histórico compromisso das elites e do Estado brasileiro com os interesses do capital internacional.

Em entrevista à Revista Carta Capital, o economista Miguel Bruno (apud DIAS, 2008, p. 32-33) afirma que "não existe uma única forma para se aderir à globalização" e a decisão escolhida expressa interesses internos que lucram com as medidas adotadas. Neste sentido, o economista critica decisões do governo Fernando Henrique Cardoso (FHC), que colocaram o Brasil numa relação mais subalterna ao Sistema Financeiro Internacional que, por exemplo, a Índia ou a China.

Nesse contexto, apesar das evidências de fragilidade, de crise e de refutamento, o Estado brasileiro vem empreendendo, desde a década de 1990, uma ampla reforma neoliberal, inaugurada pela (contra) reforma do Estado, cujo marco inicial foi o Plano Diretor de Reforma do Aparelho do Estado (PDRE), segundo o qual as conquistas da Constituição Federal de 1988 representariam "um retrocesso burocrático sem precedentes” (BRASIL/MARE, 1995, p. 27).

A execução do Plano conjugou dois prinicipais elementos que expressam o compromisso do Estado brasileiro com o desmonte dos direitos sociais e com o beneficiamento ao setor privado: a privatização tem sido uma larga estratégia de mercantilização dos serviços públicos e a publicização trata-se de uma estratégia de refilantropização da proteção social brasileira, apoiando a desresponsabilização do Estado e a responsabilização da Sociedade Civil no que diz respeito ao enfrentamento da questão social, através das ações de solidarismo, ao tempo em que amplia o acesso a recursos públicos por entidades privadas, em especial, as de cunho filantrópico.

A reestruturação produtiva vem sendo amplamente acolhida e expressa nos fenômenos da terceirização, da informalização e do 
"empreendedorismo"10; como substrato ideológico, converte-se, também, numa individualização de demandas, reforçada pelos apelos ao individualismo e à alta competitividade, quebrando os laços de solidariedade de classe historicamente construídos e, assim, inviabilizando a elaboração e defesa de projetos societários alternativos ao capital (SILVA, 2000). Para Mantega e Silva (apud BEHRING, 2003, p. 217):

setores dos trabalhadores, pressionados por essa forma predatória de reestruturação, pelo crescente desemprego, pela precarização das condições de trabalho, também desfocaram sua ação e colocaram-se na defensiva.

Marques e Mendes (2007) indicam que apesar da discreta queda na taxa média de desemprego, entre 2004 e 2005, há uma redução do rendimento médio real do trabalhador formal e uma concentração dos ocupados nas faixas de renda mais baixas.

Esses autores alertam que os determinantes da pobreza no país não foram alterados e que "a história da acumulação brasileira indica [...] uma lógica perversa, de forma que, seja qual for o desempenho da economia, a desigualdade aumenta e, com ela o tamanho da pobreza" (MARQUES e MENDES, 2007).

Para o próprio Instituto de Pesquisa Econômica Aplicada (IPEA, 2007), a desigualdade social, hoje, pode ser considerada maior que a de 1990, quando levamos em conta que, a despeito dos crescentes aumentos de salário, a participação dos trabalhadores na renda nacional $(41,7 \%)$ é menor que naquela década $(45,4 \%)$.

10 Segundo o Serviço Brasileiro de Apoio às Micro e Pequenas Empresas (SEBRAE, 2007), a abertura de micro e pequenas empresas no Brasil cresceu 22,1\% entre os anos de 2000 e 2004 . No entanto, $56 \%$ delas entram em processo de falência antes de completar cinco anos, devido à ausência de gestão e planejamento adequados, à insuficiência de políticas de apoio e à "conjuntura econômica deprimida" (IPEA, 2007). 
Nessa linha, segundo Pinheiro (2007), 17\% da População Economicamente Ativa do Brasil vive em situação de pobreza, enquanto o país mantém-se o $8^{\circ}$ pior do mundo em distribuição de renda, pois, dentre os mais de 180 milhões de brasileiros, a renda de cerca de apenas cinco mil famílias equivale a aproximadamente $45 \%$ do PIB nacional (BRAMI-CELENTANO; CARVALHO, 2007).

Esses dados evidenciam o recrudescimento da questão social brasileira, ao tempo em que nos conduzem a uma tentativa de analisar a proposta do capital para o seu enfrentamento.

\section{A proposta do capital para a (des)proteção social brasileira}

$\mathrm{Na}$ conjuntura da ofensiva neoliberal, instaurada a partir dos anos de 1990, no Brasil, o capital (re)tomou como pressupostos da cidadania os critérios de mérito e de competência, em detrimento da necessidade, do direito, da justiça e da seguridade e propõe que o enfrentamento da questão social se dê através de um mix entre o mercado, o Estado e o solidarismo (SILVA, 2000a; 2000b).

Nessa perspectiva, o mercado deve voltar-se para o cidadão consumidor $^{11}$ : aquele que por mérito e competência pessoal tornou-se apto a adquirir serviços privados de primeira qualidade, como saúde, educação e previdência. O Estado, através de uma assistência pública básica - emergencial, focalizada e seletiva - deve voltar-se para o cidadão pobre: aquele que, apesar de inserido no mundo do trabalho, não está apto a comprar tais serviços. Finalmente, pela via do solidarismo seriam atendidos aqueles que estão excluídos dos benefícios do trabalho, do mercado e do

11 Para a compreensão do conceito e da configuração desse novo sujeito de cidadania, proposto pela ofensiva neoliberal, recomendamos a leitura de Mota (1995). 
Estado, socorridos pela iniciativa esporádica e espontaneísta de uma extensa rede de solidariedade.

Desde meados da década de 1990, com maior êxito nas duas últimas gestões presidenciais, essa proposta, que concilia estratégias de mercadorização, assistencialização e refilantropização, vem tomando corpo na política social brasileira através da privatização crescente da educação, saúde e previdência, ao tempo em que, no âmbito da ação pública, a oferta desses serviços se dá de forma sucateada, seletiva e focalizada; e através da hipertrofiação da assistência social - com forte viés filantrópico - a qual passa a substituir o compromisso do Estado com qualquer perspectiva de universalização das demais políticas sociais públicas.

Um estudo recente do IPEA, que analisa dados comparativos de concentração de renda entre dezessete países da América Latina, aponta que o indicador de desigualdade brasileiro - considerando a comparação de um conjunto de indicadores de administração, saúde, educação, equidade e desempenho econômico - só não é pior que o da Bolívia e que, dentre os países analisados, o Brasil apresentou o maior percentual de gasto público (37,5\% do PIB); no entanto, a fatia desses recursos destinada ao pagamento de juros da dívida pública $(6,8 \%)$ foi maior que aquelas destinadas aos gastos sociais, como educação $(4,38 \%)$, previdência $(6 \%)$ ou saúde $(3,3 \%)$ (IPEA, 2007); evidenciando seu maior compromisso com setores privados - nacionais e internacionais -, em detrimento das políticas sociais públicas.

\section{O Estado brasileiro no pós-crash: estreitamento dos laços de solidariedade ao mercado}

No contexto do pós-setembro/2008, o Estado brasileiro vem fortalecendo seus vínculos com o setor privado, em especial, através de subsídios à produção e ao crédito. Segundo Pinheiro (2008c, p. 40), as montadoras de veículos teriam acesso - ainda nos dois 
últimos meses daquele ano - a um incentivo no valor de 8 bilhões de reais, metade deles garantida pelo governo do estado de São Paulo. Entre julho e outubro do mesmo ano, o empréstimo ao setor de agro-negócio cresceu 30\% em relação ao mesmo período do ano anterior, somando um total de 8,6 bilhões de reais (SIQUEIRA; PINHEIRO, 2008). Os bancos públicos - Banco do Brasil (BB) e Caixa Econômica Federal (CEF) - têm sido "as principais armas para eliminar os gargalos à produção em áreas como a agricultura, a construção civil e a fabricação de automóveis"; autorizados, inclusive (pela MP443), a comprar ações ou assumir controle total de empresas em dificuldades (p. 39).

Em reação, o setor privado da construção civil reivindicou incentivos que lhe garantisse liquidez, antes que chegasse a ter dificuldades financeiras. Foi atendido com uma autorização de que a CEF ofereça entre 3 a 5 bilhões de reais dos recursos captados em caderneta de poupança parar criar linhas de capital de giro e comprar títulos garantidos por receitas futuras do setor.

Apenas essas medidas - dentre outras que não foram relacionadas neste texto - somam um montante de cerca de 20 bilhões de reais, antecipados ao setor privado, como estratégia central de "preservar a saúde do sistema financeiro"12. Por outro lado, o FED disponibilizou ao Brasil - bem como à Cingapura, México e Coréia do Sul - um empréstimo de 30 bilhões de dólares, que pode ser contraído até abril de 2009. A oferta é, antes de tudo, uma estratégia norte-americana para preservar o dólar como

12 Lembramos aqui que, em setembro de 2007, o Sistema Único de Saúde (SUS) entrou em colapso em todo o país, registrando óbitos em vários estados, decorrentes do sucateamento dos serviços; das greves dos médicos e residentes e da sub-remuneração desses profissionais e, somente após esse quadro drástico, é que o Governo Federal liberou, através do Ministério da Saúde, o complemento de 1,2 bilhões de reais, para corrigir a tabela do SUS em todo o Brasil e, assim "preservar o funcionamento do sistema". 
moeda-referência das transações internacionais (idem, p. 40-41) ${ }^{13}$. Em outras palavras, alertamos que a contração de tal empréstimo poderá, mais uma vez, reforçar os vínculos do Estado brasileiro com os interesses privados e externos.

\section{Considerações finais: $o$ acirramento das disputas pelo acesso aos recursos públicos como pressuposto exclusivo do capital e as ameaças à sobrevivência da humanidade}

Entre economistas e jornalistas, diversas têm sido as comparações, aproximações e alinhamentos entre o crash de setembro de 2008 e a crise de 1929. O que só é possível numa perspectiva exclusivamente financeira, pois, do ponto de vista político, as correlações de forças atuais são inteiramente diversas daquelas do início do século passado. Apenas para elencar alguns elementos de extrema divergência, lembramos que a Alemanha, àquela época, vivia um estrondoso movimento socialista (cujo fracasso conduziu à ascensão do nazismo); desempregados e veteranos de guerra ergueram uma favela em plena Washington; havia conflitos entre desempregados e exércitos; o sindicalismo e as idéias socialistas floresciam e expandiam-se no mundo inteiro.

13 Para Belluzzo (2009, p. 32), "a faculdade de usar sua moeda como meio de pagamento universal [instituída desde Bretton Woods] conferiu e ainda vem conferindo aos EUA grande flexibilidade na gestão da política monetária e na administração dos balanços de pagamento". 
Para Leblon (2008), aquela correlação de forças - à época da crise de 1929 - conduziu ao new deal, com sua regulação estatal dos mercados financeiros, e ações estatais de enfrentamento à pobreza e de promoção de bem estar. Mas, na conjuntura do crash/2008:

É a ausência dessa mesma correlação que dá ao atual secretário do Tesouro norte-americano, Henry Paulson, a liberdade de um bombeiro vesgo, cuja mangueira só enxerga a cobertura do edificio e ignora as chamas que devoram os andares debaixo (LEBLON, 2008).

Com essa analogia, o jornalista adverte que, na ausência de uma proposta consistente das esquerdas, as respostas vêm da direita e beneficiam, prioritária ou exclusivamente, ao próprio capital e aos próprios causadores da crise. De fato, parece-nos que há um consenso inédito de que o Estado deve ser interventor e regulador; no entanto, a nosso ver, frente à fragilidade da organização do trabalho e à ausência ou incipiência de uma defesa de projetos alternativos ao capital, há uma predisposição ou tendência de que as intervenções e regulações do Estado restrinjam-se, prioritária - senão exclusivamente - à esfera econômica e prenuncia-se uma radicalização da luta pelos recursos públicos em benefício exclusivo dos interesses privados. Nesta perspectiva, "o processo de centralização de capital na órbita financeira será comandado pelo Estado, respondendo aos clamores do mercado" (BELLUZZO, 2008c, p. 34), comprometendo, a nosso ver, possíveis investimentos em políticas sociais públicas.

Estas considerações e advertências agravam-se quando lembramos que as respostas do capital - teórica e historicamente - redundam na ampliação/intensificação de suas próprias contradições e limites. Assim, a crise atual diferencia-se, também, pela indicação de continuidade da intensa devastação da natureza pelo capital e pelos riscos das opções de superação da crise por vias béli- 
$\operatorname{cas}^{14}$, uma vez que ambas as questões - devastação inconseqüente da natureza e possibilidade de uma guerra de abrangência mundial - nos dias atuais, implicam em uma ameaça concreta e irrevogável à sobrevivência do planeta e da humanidade.

\section{Referências}

BEHRING, E. R. Brasil em contra reforma: desestruturação do Estado e perda de direitos. São Paulo: Cortez, 2003.

BELlUZZO, L. G. M. A gênese das crises. Revista The Economist/ Carta Capital (O Mundo em 2009). Edição Especial, Jan. 2009.

BELluZZO, L. G. M. Mantida por aparelhos. Revista Carta Capital, São Paulo, Ano XIV, n. 492, abr. 2008 a.

BELluZZO, L. G. M. Mantida por aparelhos. Revista Carta Capital, São Paulo, Ano XV, n. 513, set. 2008b.

BELluZZO, L. G. M. O problema está aqui. Revista Carta Capital, São Paulo, Ano XV, n. 514, set. 2008c.

BENJAMIM, C. Karl Marx manda lembranças. Disponível em: $<$ www.imediata.com. Acesso em: Out. 2008.

14 Vários estudiosos da atual crise alertam que esta possibilidade não está descartada. Para Chesnais (2008), por exemplo, as atuais relações entre EUA e China poderão conduzir os primeiros tanto ao reconhecimento de que sua superioridade militar é apenas um elemento subordinado de negociação, quanto a uma aventura militar de conseqüências imprevisíveis. Também para Costa (2009), a aproximação militar entre países como Rússia, Irã, Cuba, Nicarágua, Equador e Bolívia cria um problema embaraçoso para os EUA e um desafio para seu novo governo. 
BONVICINO, R. O capitalismo sem direitos do mundo.

Disponível em: < http://ultimosegundo.ig.com.br/opiniao/ regis_bonvicino/2008/07/05/o_capitalismo_sem_direitos_do_ mundo_1419269.html> Acesso em: 15 jul. 2008.

BRAMI-CELENTANO, A.; CARVALHO, C. E. A reforma tributária do governo Lula: continuísmo e injustiça fiscal. Rev. Katálysis, Florianópolis, v. 10, n. 01, jan/jun. 2007.

BRASIL. Ministério da Administração Federal e Reforma do Estado. Plano diretor de reforma do aparelho do Estado. Brasília: Ministério da Administração Federal e Reforma do Estado, 1995.

CASTEL, R. As metamorfoses da questão social: uma crônica do salário. Rio de Janeiro:Vozes, 1998.

COSTA, A. L. M. A América Latina vista por nós: o que o futuro reserva para a Região? Revista The Economist/Carta Capital $(\mathrm{O}$ Mundo em 2009). Edição Especial, Jan. 2009.

COSTA, A. L. M. O fim de uma era. Revista Carta Capital, São Paulo, Ano XV, n. 523, Nov.2008b.

COSTA, A. L. M. Retorno ao pêndulo. Revista Carta Capital, São Paulo, Ano XIV, n. 492, Abr. 2008a.

DIAS, E. F. Reestruturação produtiva: forma atual da luta de classes. Revista Outubro, São Paulo, n. 01, 1998.

DIAS, M. A armadilha do juro alto. Revista Carta Capital, São Paulo, Ano XIV, n. 492, Abr. 2008a

HARVEY, D. O novo imperialismo. São Paulo: Edições Loyola, 2004.

IPEA. Estado de uma nação: mercado de trabalho, emprego e informalidade. Disponível em www.ipea.org.br. Acesso em 14 fev 2007. 
KING, D. O estado e as estruturas sociais de bem-estar em democracias industriais avançadas. Cadernos Novos Estudos - CEBRAP, São Paulo, n. 22, out. 1988.

MARQUES, R. M.; MENDES, A. Servindo a dois senhores: as políticas sociais no governo Lula. Rev. Katálysis, Florianópolis, v. 10, n. 01, jan/ jun. 2007.

MARTINS, C. E. Da globalização da economia à questão da democracia. In: BRASIL. Ministério da Previdência e Assistência Social. Secretaria de Assistência Social. Discutindo a assistência social no Brasil: ciclo de seminários. Brasília: Ministério da Previdência e Assistência Social. Secretaria de Assistência Social, 1997.

MÉSZÁROS, I. Para além do capital: rumo a uma teoria de transição. São Paulo: Boitempo, 2002.

MOTA, A. E. Cultura da crise e seguridade social: um estudo sobre as tendências da previdência e da assistência social brasileiras nos anos 80-90. São Paulo: Cortez, 1995.

PINHEIRO, M. O novo socialismo. Revista Carta Capital, São Paulo, ano XV, n. 514, set. 2008a.

PINHEIRO, M. Pacote remendado. Revista Carta Capital, São Paulo, ano XV, n. 516, out. 2008b.

PINHEIRO, M. Pacote remendado. Revista Carta Capital, São Paulo, ano XV, n. 523, nov. 2008c.

SILVA, S. S. S. A atuação do conselho municipal de assistência social do Recife frente à ofensiva neoliberal. 2000.105 f. Dissertação (Mestrado em Serviço Social). Universidade Federal de Pernambuco, Recife, 2000a.

SILVA, S. S. S. A esfera pública: a ofensiva neoliberal e a questão social no Brasil. Revista Pesquisa em Debate. Recife, p. 56-62, 2000 b.

SIQUEIRA, A.; PINHEIRO, M. Navegação na neblina. Revista Carta Capital, São Paulo, ano XV, n. 520, Nov. 2008. 